\title{
Application of Yang-Monti Principle in Ileal Ureter Substitution: Is It a beneficial Modification?
}

\author{
M. Esmat, A. Abdelaal, D. Mostafa \\ Department of Urology, Ain Shams University, Cairo, Egypt
}

\section{ABSTRACT}

Purpose: Ureteric substitution using the Yang-Monti principle was reported as a modification of simple ileal ureter replacement. In this study, we evaluate its safety, surgical outcome and impact on renal function.

Materials and Methods: Sixteen patients underwent ileal ureter replacement using the Yang-Monti principle to overcome long ureteric defects. Exclusion criteria included patients with elevated serum creatinine $>1.8 \mathrm{mg} / \mathrm{dL}$, inflammatory bowel syndrome or irradiated bowel. Antireflux implantation into the bladder was performed in 12 patients while 4 patients with intact healthy lower ureters underwent distal ileal-ureteral anastomosis. Follow-up protocol was carried out for up to 3 years in 9 patients.

Results: No intra-operative or postoperative mortality or significant complications occurred. There were minor complications in the form of urinary leakage that necessitated prolonged ureteric stenting in one patient, superficial wound infection in another one and 3 patients developed treatable urinary tract infection without late harmful effects. During follow up, no excess mucus production or metabolic abnormalities were encountered. All patients had preserved renal function (improved in 13 patients and stabilized in 3) without any evidence of urinary obstruction.

Conclusions: The reconfigured ileal segment for ureteric substitution is a safe technique with an excellent outcome. It uses short ileal segments for reconstruction of an ileal tube of adequate length and optimal caliber that permits easy antireflux implantation into the bladder so it is not associated with excess mucus production or metabolic abnormalities and offers a durable preservation of renal function without urinary obstruction.

\section{ARTICLE INFO}

Key words:

Ureter, lleum;

Urethral Stricture

Int Braz J Urol. 2012; 38: 779-87

Submitted for publication:

March 21, 2012

Accepted after revision:

July 04, 2012

\section{INTRODUCTION}

Long ureteric defects may occur as a result of iatrogenic ureteral injuries, recurrent pelvi-ureteric junction obstruction, chronic inflammatory diseases such as bilhariziasis, retroperitoneal fibrosis and ureteral carcinoma. Several techniques were described to compensate this defect by intrinsic urinary tissue such as direct anastomosis, psoas hitch, Boari flap, transuretero-ureterostomy and renal autotransplantation.
In some occasions the ureteral defect is too long to the degree that extra urinary tissue is needed to overcome it. Accordingly, other alternatives have been tried such as artificial ureteral substitutes e.g. Gore-Tex tube graft (1) which showed disappointing results in contrast to the promising ones that were achieved with the use of pedicled bowel grafts (2). The most commonly used technique is that of ileal ureter replacement which was first described by Schoemaker in 1906 (3) and gained wide acceptance later on. One of 
the modifications of this technique was the application of Yang-Monti principle $(4,5)$ which allowed the creation of a long tube from short bowel segment after its reconfiguration. It was applied for ureteral replacement first in dogs (6) then clinically (7) in few reports. In this study, we report our experience with ileal ureter substitution using the Yang-Monti principle with follow-up data for up to 3 years.

\section{MATERIALS AND METHODS}

The current study was performed from 0ctober 2005 till February 2010. Patients with long ureteral defects that could not be repaired using the intrinsic urinary tissue were included in this study. Elevated serum creatinine $>1.8 \mathrm{mg} / \mathrm{dL}$, inflammatory bowel syndrome, irradiated bowel or a non functioning renal unit were considered as exclusion criteria.

All patients underwent preoperative evaluation in the form of careful history taking, medical examination and laboratory investigations which included complete urine analysis, serum creatinine, sodium, potassium and chloride and PH level estimation. Radiological investigations to visualize the upper urinary tract included renal ultrasonography, intravenous urography or magnetic resonance urography. Renal isotope scanning was performed to estimate the split renal function.

The study was approved by the ethical committee of Ain Shams University. All patients were consented for approval of surgery and underwent preoperative colonic preparation for 48 hours.

\section{Technique}

Isolation of $5-7.5 \mathrm{~cm}$ of the terminal ileum on their vascular bed was performed according to the length required to compensate the ureteral defect. Then, according to the Yang-Monti principle, the isolated ileal segment was further subdivided into 2-3 equal parts (each $2.5 \mathrm{~cm}$ in length) with preservation of the individual blood supply (Figure-1). The continuity of the ileum was reestablished. Each ileal segment was incised at its longitudinal axis close to the mesenteric border. Unfolding of the incised segments with suturing
Figure 1 - Isolation of 2 ileal segments on their mesenteric pedicle.

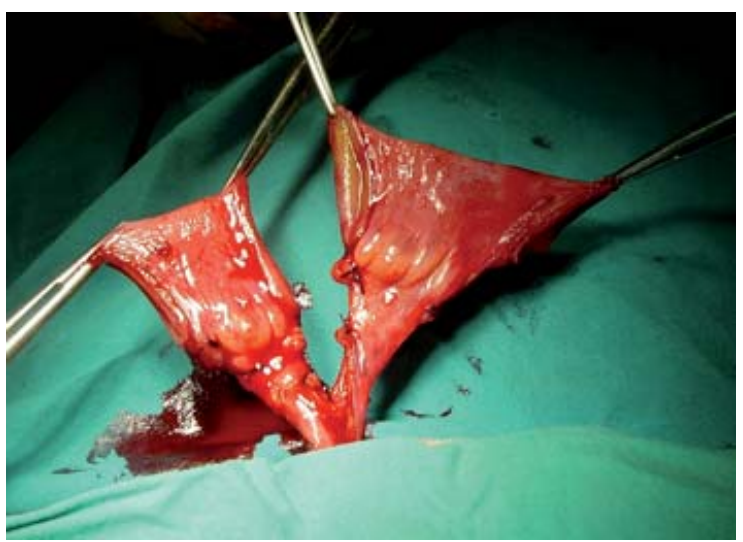

of their adjacent ends were performed and resulted in the formation of an intestinal plate $2.5 \mathrm{~cm}$ wide and 12-18 $\mathrm{cm}$ long (according to the number of isolated ileal segments) (Figure-2). This plate was tubularized around 16F Nelaton catheter using 4/0 absorbable sutures (Figure-3). The proximal end of the ileal tube was anastomosed to the ureter or renal pelvis while the distal end was anastomosed

Figure 2 - Unfolding of the incised ileal segments with suturing of their adjacent ends.

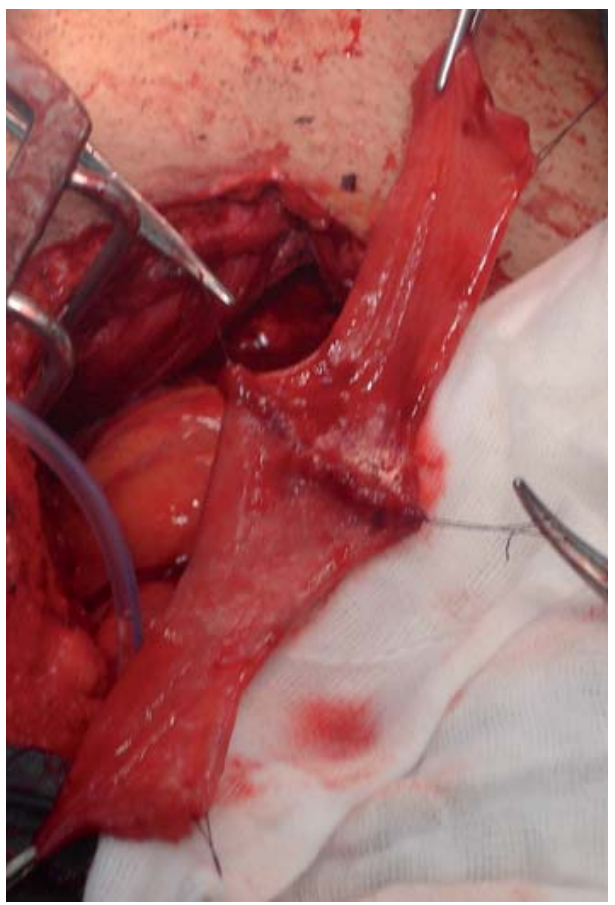


Figure 3 - Tubularization of the incised ileal segments.

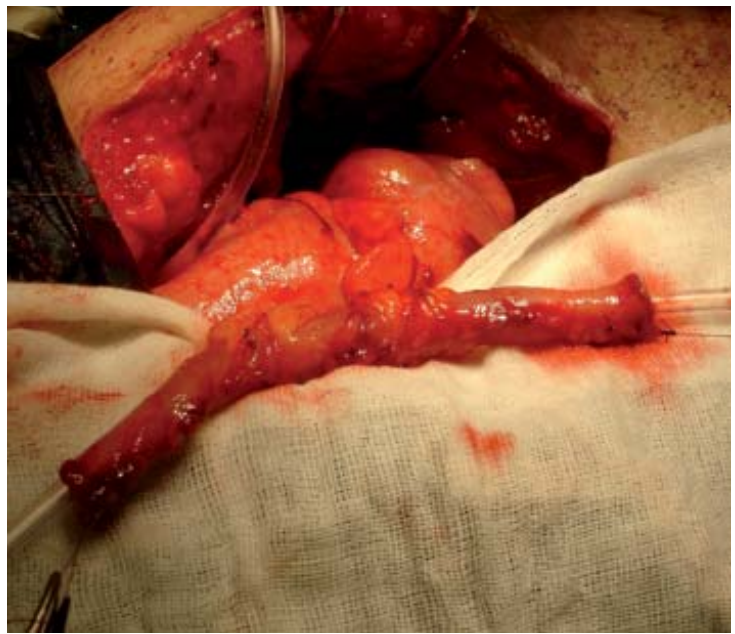

either to the bladder using a non refluxing Lich-Gregoir technique (Figures 4 and 5) or to the spatulated cephalic end of the lower ureter in cases with the presence of an intact healthy lower ureter. At the end of the procedure, a ureteric silicon stent and a urethral catheter were left for 3 weeks and 10 days respectively.

Figure 4 - Anastomosis of the ileal tube to bladder mucosa.

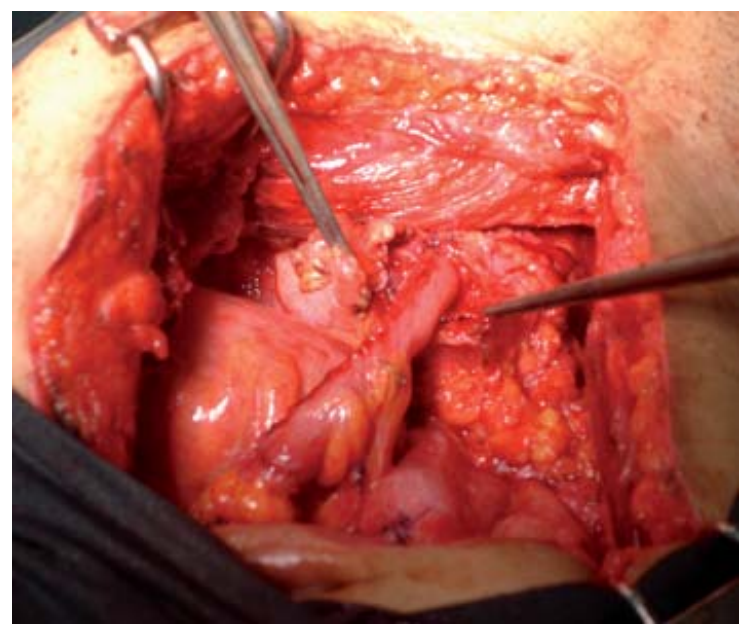

Follow-up was carried out at 3 months postoperatively then annually thereafter and included estimation of serum creatinine, sodium, potassium and chloride and $\mathrm{PH}$, isotope renal scanning and imaging of upper urinary tract. Ascending cysto-
Figure 5 - Reapproximation of detrusor layer to create a submucosal tunnel.

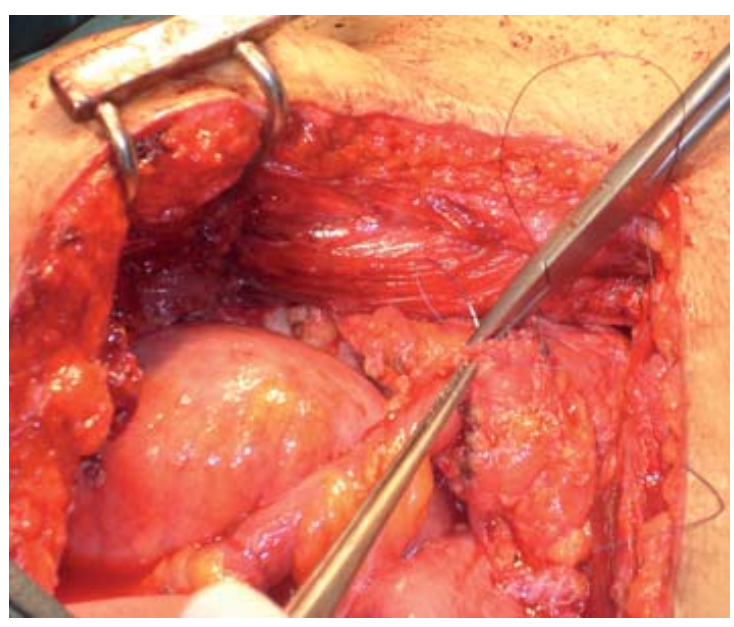

graphy was performed only for patients who underwent ileal tube implantation into the bladder at 6 months postoperatively.

\section{Statistical methods}

IBM SPSS statistics (V. 19.0, IBM Corp., USA, 2010) was used for data analysis. Data were expressed as "Mean \pm SD" for quantitative parametric measures. Paired t-test was used for comparison between 2 dependent groups. The probability of error at 0.05 was considered significant.

\section{RESULTS}

The study included 16 patients (13 males and 3 females). Their age ranged from 23 - 57 years (mean: $35 \pm 8$ years). They presented with loin pain secondary to ureteric stricture, lumbar urinary fistula or pyelonephritis. All patients had a long ureteral defect which was secondary to bilharziasis in 2 cases or iatrogenic injury in 14 cases [12 after urologic procedures, one post hysterectomy and one post surgical excision of sigmoid tumor (for whom percutaneous nephrostomy and antegrade study were performed)].

Intraoperatively, we used 2 - 3 ileal segments ( 2 in 13 and 3 in 3 patients) to create a tube about $12-18 \mathrm{~cm}$ in length and of a reasonable caliber $(16 \mathrm{CH})$ to overcome the ureteral defect. 
Antireflux implantation of the ileal tube into the bladder was performed in 12 patients while 4 patients with intact healthy lower ureter underwent distal ileoureteral anastomosis. No intraoperative complications occurred.

Postoperative follow-up showed no intestinal complications or significant morbidity. With application of The Clavien-Dindo Classification of Surgical Complications (8), early postoperative complications were minor in the form of prolonged urinary leakage in one case (6\%) (grade I), superficial wound infection in another one (6\%) (grade I), and uncomplicated UTI in 3 patients (18\%) (grade II) that were managed properly without late harmful sequelae. No metabolic abnormalities occurred in any patient during early postoperative period.

Follow-up was carried out for up to 3 years (ranged 6-36 months). At 3 months postope- to the lower ureter. Radioisotope scanning showed split renal function improvement in 13 patients and stable in 3 with no evidence of urinary obstruction in anyone (Table-1). Ascending cystography revealed first degree reflux in one patient. Follow-up was continued for 3 years in 9 patients who showed maintained renal function without metabolic complications or recurrent urinary tract infections (Table-2).

\section{DISCUSSION}

Nowadays, iatrogenic ureteral trauma showed an increased incidence as one of the causes of ureteric stricture $(9,10)$. This could occur as a result of direct injury or focal ischemia to the ureter (11). Most of our cases (14/16) had a history of a complicated iatrogenic ureteral injury or stricture with an inserted percutaneous nephrostomy to

Table 1 - Preoperative and 3 months postoperative results of laboratory investigations and split renal function.

\begin{tabular}{|c|c|c|c|c|c|}
\hline & $\mathrm{N}$ & $\begin{array}{l}\text { Preoperative } \\
\text { (mean } \pm \text { SD) }\end{array}$ & $\begin{array}{c}3 \text { months postoperative } \\
(\text { mean } \pm \text { SD })\end{array}$ & $t$ & $P$ \\
\hline Mean serum creatinine (mg/dL) & 16 & $1.13 \pm 0.24$ & $1.006 \pm 0.16$ & 4.226 & 0.001 \\
\hline Split renal function & 16 & $37.69 \pm 1.92$ & $41.13 \pm 1.54$ & -16.893 & 0.0 \\
\hline Mean serum sodium & 16 & $138.06 \pm 2.59$ & $137.94 \pm 1.65$ & 0.251 & 0.8 \\
\hline Mean serum potassium & 16 & $4.21 \pm 0.42$ & $4.17 \pm 0.35$ & 1.385 & 0.18 \\
\hline Mean serum chloride & 16 & $103.38 \pm 2.89$ & $104.19 \pm 3.58$ & -1.8 & 0.09 \\
\hline $\mathrm{PH}$ & 16 & $7.39 \pm 0.01$ & $7.39 \pm 0.00$ & -2.334 & 0.034 \\
\hline
\end{tabular}

ratively, improvement of serum creatinine among all patients with no electrolyte disturbance or metabolic acidosis were noticed. No complaint of excess mucous production was noticed. Imaging of the upper urinary tract showed improvement of renal dilatations in 12 patients and stable renal configuration in 4 . We noticed transient stagnation of the dye at the distal ileoureteral anastomosis without upper tract dilatation followed by complete evacuation of the dye into the bladder among the four cases with distal ileal anastomosis preserve renal function till time of surgical repair and to perform an antegrade study. All cases had a ureteric defect that was too long to be repaired using internal urinary tissue and so the decision of ileal ureter substitution was taken to compensate this defect.

Ileal ureter replacement became now an established procedure for ureteric reconstruction especially after the urologists gained more experience in bowel surgery (12). Several studies reported encouraging results regarding surgical ou- 
Table 2 - 3 months and 3 years postoperative results of laboratory investigations and split renal function.

\begin{tabular}{lccccc}
\hline & N & $\begin{array}{c}3 \text { months postoperative } \\
\text { (mean } \pm \text { SD) }\end{array}$ & $\begin{array}{c}3 \text { years postoperative } \\
(\text { mean } \pm \text { SD) }\end{array}$ & t & P \\
\hline Mean serum creatinine $(\mathrm{mg} / \mathrm{dL})$ & 9 & $1.011 \pm 0.2$ & $0.989 \pm 0.2$ & 0.8 & 0.44 \\
Split renal function & 9 & $41.56 \pm 1.66$ & $40.78 \pm 1.39$ & -0.8 & 0.44 \\
Mean serum sodium & 9 & $137.22 \pm 1.39$ & $138.56 \pm 1.74$ & -0.66 & 0.52 \\
Mean serum potassium & 9 & $4.10 \pm 0.35$ & $4.12 \pm 0.32$ & 0.0 & 1 \\
Mean serum chloride & 9 & $104.89 \pm 3.4$ & $105 \pm 3.46$ & -0.13 & 0.9 \\
PH & 9 & $7.397 \pm 0.0$ & $7.395 \pm 0.00$ & 0.8 & 0.44 \\
\hline
\end{tabular}

tcome and renal function $(2,10)$, however common drawbacks were reported mostly attributed to the absorbing and secreting criteria of the involved ileal segment such as hyperchloremic metabolic acidosis and excess mucus production and also to the wide caliber refluxing ileal ureter with subsequent progressive dilatation, functional obstruction and recurrent UTI $(10,13)$. So, to overcome these complications and to improve the surgical outcome, the Yang-Monti principle was applied as a modification of original simple ileal ureter replacement, which allowed the reconstruction of long tube from a reconfigured short bowel segment and the ability of antireflux implantation of the reconfigured ileal tube into the bladder. The criticism to this idea was the fear of impaired urine transport through the reconfigured ileal tube, however a dynamic unidirectional flow of urine was reported using cineradiographic studies in a study that explained this by a decrease in tube diameter and reorientation of the 2 muscle layers of the ileal tube after its reconfiguration (7).

Intraoperatively, we used 2 ileal segments in 13 patients. Each ileal segment provided a tube of about $6 \mathrm{~cm}$ length after reconfiguration. 3 patients needed 3 ileal segments to compensate the ureteric defect. We found that the addition of a third ileal segment can be done successfully without complications with better results than performing the anastomosis under tension with a risk of subsequent stenosis. On the other hand, extra length of the ileal tube can lead to redundancy and functional obstruction, so adjustment of the ileal tube length is advisable to prevent such complications.

We found that this technique is safe as it was not associated with mortality or significant morbidity. Postoperative complications were minor in the form of prolonged urinary leakage in one case for 3 weeks that was managed conservatively by temporary urinary diversion through the preoperative nephrostomy tube and postponing removal of ureteric stent for 5 weeks with no late harmful effects, superficial wound infection in one patient that was managed by repeated dressing and secondary suturing of the skin and subcutaneous tissue under local anesthesia and uncomplicated urinary tract infections (UTI) in 3 patients that was treated by proper antibiotics. Other authors also reported absence of any mortality or significant morbidity following this procedure $(7,14)$.

During follow-up, no complaint of excess mucus production was observed which was also noticed by other authors that used the same procedure $(7,15)$. This observation is considered an advantage of this modification and most probably due to the marked reduction in the size of the secreting surface area in comparison to simple ileal ureter that may be associated with mucous obstruction in some cases (13). Moreover, hyperchloremic metabolic acidosis did not occur in our 
series, however it was reported by various studies using simple ileal ureter in varying percentages $(9,10)$. Absence of metabolic disorders among our cases can be explained by proper selection of patients (serum creatinine $\leq 1.8 \mathrm{mg} \%$ ), reduction of the size of absorbing surface area and the antireflux implantation of the reconfigured ileal tube which decreased the contact of urine with the ileal mucosa.

The importance of antireflux implantation of the simple ileal ureter remains a controversial issue; some authors recommended it (13) and found that refluxing anastomosis was harmful (16) while others reported no difference in outcome as the natural isoperistaltic waves of simple ileal ureter can prevent reflux from reaching the kidney (7) and an ileal loop longer than $15 \mathrm{~cm}$ was considered a safe guard against the harmful effect of reflux on the kidney (17). Other authors tried to prevent reflux by construction of an intussuscepted distal nipple valve, however complications occurred in the form of desussception of the valve and stone formation at the intussuscepted segment (18). In our series, we applied antireflux implantation of the ileal tube in 12 patients with excellent results in reflux prevention which was facilitated by the reasonable caliber of the reconfigured ileal tube $(16 \mathrm{CH})$ and the asymmetrical incision of the ileal segment that led to creation of an ileal tube with ends free of mesentery. Follow-up of our cases revealed no graft dilation, recurrent UTI or metabolic acidosis so we thought that antireflux implantation of the reconfigured ileal tube is advisable as it is now easy to perform, can prevent pressure transmission to the kidney and progressive graft dilation with subsequent functional obstruction, decreases the incidence of recurrent UTI and metabolic acidosis and subsequently attributes to preservation of renal function.

Four cases with intact lower ureter were included in our series. Intraoperatively, we had to choose between preservation of the lower ureter with distal ileoureteral anastomosis or to sacrifice it, add another reconfigured bowel segment and perform ileovesical anastomosis. We chose the preservation of the lower ureter as we found it healthy, had good vascularity, non refluxing and of adequate length (about $7-8 \mathrm{~cm}$ ) so, we performed ureteric spatulation and end to end anastomosis to the ileal tube which was facilitated by the reasonable caliber of the reconfigured tube. Follow-up imaging of these cases showed transient stagnation of dye at the distal anastomosis followed by complete evacuation of the dye into the bladder without renal or graft dilatation. Renal isotope scanning showed improvement of split renal function without urinary obstruction in any patient so we found that distal ileoureteral anastomosis can be done successfully with no worry about organic or functional obstruction in carefully selected cases. This was facilitated by the diminished caliber of the ileal tube after its reconfiguration which added another advantage to Yang-Monti modification.

The main target of any technique for ureteric substitution is to preserve the renal function. Follow-up of our patients by isotope renal scanning and upper tract imaging revealed improvement of renal function and renal configuration in most patients while the rest showed stabilized renal function without evidence of urinary obstruction or progressive renal or graft dilation in any patient and this outcome was durable and maintained all over the follow-up. Other authors that used the Monti principle also reported preserved renal function during their short term follow-up $(7,14)$. We thought that this excellent functional outcome was obtained as a result of gaining the proponents of this procedure that led to absence of organic or functional urinary obstruction, easy antireflux implantation into the bladder or distal end to end anastomosis to lower ureter and less incidence of recurrent UTI which were aided by proper selection of cases.

\section{CONCLUSIONS}

In conclusion, we advice the use of Yang-Monti principle in ileal ureter replacement as it consumes a short bowel segment with less mucus production and absence of metabolic abnormalities. It also leads to creation of a long tube of reasonable diameter with easy antireflux implantation. Moreover, it is a safe technique without significant morbidity that permits a durable preservation of renal function. Distal ileoureteral 
anastomosis can be performed successfully in carefully selected cases.

\section{CONFLICT OF INTEREST}

None declared.

\section{REFERENCES}

1. Baltaci S, Ozer G, Ozer E, Soygür T, Be alti O, Anafarta K: Failure of ureteral replacement with Gore-Tex tube grafts. Urology. 1998; 51: 400-3.

2. Chung BI, Hamawy KJ, Zinman LN, Libertino JÁ: The use of bowel for ureteral replacement for complex ureteral reconstruction: long-term results. J Urol. 2006; 175: 179-83; discussion 183-4.

3. Shoemaker J: Discussie op voordracht van J.M. van Damn over interaabdominale plastiken. Ned Tijdschr Geneesk. 1911; 836.

4. Yang WH: Yang needle tunneling technique in creating antireflux and continent mechanisms. J Urol. 1993; 150: 830-4.

5. Monti PR, Lara RC, Dutra MA, de Carvalho JR: New techniques for construction of efferent conduits based on the Mitrofanoff principle. Urology. 1997; 49: 112-5.

6. D`Elia G, Ali-El-Dein B, Thuroff J, El-Mekresh M, El-Baz M, Ghoneim MA: Reconfigured anti-reflux ileal ureter: a novel surgical technique. BJU Int 2001; 88 (Suppl): 75.

7. Ali-el-Dein B, Ghoneim MA: Bridging long ureteral defects using the Yang-Monti principle. J Urol. 2003; 169: 1074-7.

8. Dindo D, Demartines N, Clavien PA: The Clavien-Dindo classification of surgical complications. Ann Surg. 2004; 244: 931-7.

9. Armatys SA, Mellon MJ, Beck SD, Koch MO, Foster RS, Bihrle R: Use of ileum as ureteral replacement in urological reconstruction. J Urol. 2009; 181: 177-81.

10. Verduyckt FJ, Heesakkers JP, Debruyne FM: Long-term results of ileum interposition for ureteral obstruction. Eur Urol. 2002; 42: 181-7.

11. Yates DR, Mehta SS, Spencer PA, Parys BT: Combined antegrade and retrograde endoscopic retroperitoneal bypass of ureteric strictures: a modification of the 'rendezvous' procedure. BJU Int. 2010; 105: 992-7.

12. Boxer RJ, Fritzsche P, Skinner DG, Kaufman JJ, Belt E, Smith RB, et al.: Replacement of the ureter by small intestine: clinical application and results of the ileal ureter in 89 patients. J Urol. 1979; 121: 728-31.

13. Bonfig R, Gerharz EW, Riedmiller H: Ileal ureteric replacement in complex reconstruction of the urinary tract. BJU Int. 2004; 93: 575-80.

14. Rodríguez Alonso A, González Blanco A, Suárez Pascual G, Bonelli Martín C, Lorenzo Franco J, Cuerpo Pérez MA: Partial substitution of the ureter using a short segment of the ileum following the Monti procedure. Actas Urol Esp. 2005; 29: 607-10.

15. Castellan M, Gosalbez R: Ureteral replacement using the Yang-Monti principle: long-term follow-up. Urology. 2006; 67: 476-9.

16. Tanagho EA: A case against incorporation of bowel segments into the closed urinary system. J Urol. 1975; 113: 796-802.

17. Waldner M, Hertle L, Roth S: Ileal ureteral substitution in reconstructive urological surgery: is an antireflux procedure necessary? J Urol. 1999; 162: 323-6.

18. Shokeir AA, Ghoneim MA: Further experience with the modified ileal ureter. J Urol. 1995; 154: 45-8.

Correspondence address: Dr. Mohamed Esmat Department of Urology, Ain Shams University, Cairo, Egypt

Fax: + 202 2690-4430 E-mail: m_esmat_2000@yahoo.com 


\section{EDITORIAL COMIMENT}

The authors present one more series confirms that the use of intestinal segments reconfigured by the Yang-Monti technique as alternative ureteral replacement.

Their results confirm those published in the literature. Alternatives to the technique used, but always based on the principle of Monti, are modified spiral Casale (1) and the use of intestinal segments in series to achieve the same purpose as Ghoneim (2). The use of the variation of Casale allows to obtain intestinal with conduits and vascular pedicle free ends in its middle portion and does not require performing a circular anastomosis for joining two segments, as is customary when using the technique of Yang-Monti original.

\section{REFERENCES}

1. Casale AJ: A long continent ileovesicostomy using a single piece of bowel. J Urol. 1999; 162: 1743-5.
2. Ali-el-Dein B, Ghoneim MA: Bridging long ureteral defects using the Yang-Monti principle. J Urol. 2003; 169: 1074-7.

Dr. Marcelo P. Braz Serviço de Urologia Hospital Federal de Bonsucesso E-mail:drmarcelo.braz@gmail.com 


\section{EDITORIAL COMMENT}

Initially, the use of reconfigured ileal tube was described for the replacement of an unavailable cecal appendix, used as efferent conduit for catheterization in continent urinary cutaneous diversions according to Mitrofanoff (references 4 and 5). Pope and Koch were the first to describe the replacement of the right ureter with a single $2 \mathrm{~cm}$ segment of reconfigured ascending colonic segment, resulting in a tube of $12 \mathrm{~cm}$ (1). The use of ileal segments between the kidney and the bladder has several side effects, well described in the text, and they are avoided with the use of the proposed technique, due to the minimal surface of intestinal mucosa exposed to urine. The reconfigured ileal segment allows the use of correct caliber and extension for each case; a $2.5 \mathrm{~cm}$ segment of ileum results in a tube of $6 \mathrm{~cm}$. Usually a double tube $(12 \mathrm{~cm})$ associated with a psoas

\section{REFERENCES}

1. Pope J, Koch MO: Ureteral replacement with reconfigured colon substitute. J Urol. 1996; 155: 1693-5. hitch is sufficient to replace the lost segment. Anti-reflux technique and interposition of the ureteral inferior and superior stubs are feasible due to the small caliber of the tube. The concern of the loss of the peristaltic movements of the tube due to the reconfiguration (transforming longitudinal muscular fibers in transverse fibers and vice-versa) has no ground, since dynamic image studies showed that there is a unidirectional flow of urine, with preservation of the peristaltic capacity (reference 7). The loss of long ureteral segments has a high morbidity and is becoming more frequent due to the large use of ureterorrenoscopy. In the present, as concluded by the authors, the transverse tubularization technique of ileal segments is efficient, easy to perform and with low morbidity, to replace long ureteral losses, and is superior to the use of natural ileal segments.

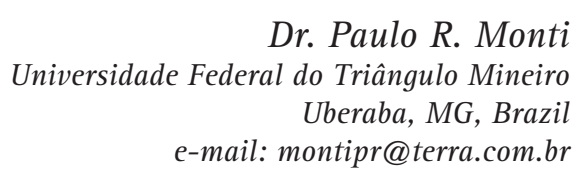

